\title{
Psychosocial Impact of Brain Injury: A Review
}

\author{
Raj Kumar $^{1}$ Arushi Kumar ${ }^{2}$ Amit Kant Singh ${ }^{1}$ \\ ${ }^{1}$ U.P. University of Medical Sciences, Saifai, Etawah, \\ Uttar Pradesh, India \\ 2Dr. Sampoorna Nand Medical College, Jodhpur, Rajasthan, India \\ Indian J Neurosurg 2019;8:11-15
}

Address for correspondence Raj Kumar, Vice Chancellor, U.P. University of Medical Sciences, Saifai 206130, Etawah, Uttar Pradesh, India (e-mail: rajkumar1959@gmail.com).

\begin{abstract}
Keywords

- traumatic brain injury

- psychiatric disorders

- psychological effects

- social effects

Traumatic brain injury (TBI) is known as "silent epidemic" because of lack of knowledge about it and its delayed symptoms of memory and cognitive problems. The incidence is approximately 1.4 million per year in the United States, and in the developing countries, it is approximately 341 per 100,000 . In the United States, the annual productivity loss due to TBI and its delayed effects is more than $\$ 56$ billion. TBIs occur mainly due to traffic accidents and falls. All the age groups are affected, but the rates are higher in men than in women. The causes vary as per the age groups as traumas affect mainly children and elderly, and traffic accidents and violence affect more of adolescents and young adults. Data from various studies indicate wide variation in the incidence and prevalence of psychiatric disorders after TBI, but they are definitely higher as compared with general population. We also noted different psychiatric disorders in post head injury cases during follow-up at our university hospital, which included depression, behavioral disorders, cognitive disorders, memory impairment, anxiety disorders, stress-related headache, vertigo, irritability and sleep disorders, etc. Therefore, this review was undertaken to assess the psychosocial impact of brain injury on an individual.
\end{abstract}

\section{Introduction}

Traumatic brain injury (TBI) is known as "silent epidemic" because of lack of knowledge about it and its delayed symptoms of memory and cognitive problems. The incidence is approximately 1.4 million per year in the United States, ${ }^{1}$ and in the developing countries, it is approximately 341 per 100,000 . In the United States, the annual productivity loss due to TBI and its delayed effects is more than $\$ 56$ billion. $^{2}$ TBIs occur mainly due to traffic accidents and falls. ${ }^{3}$ All the age groups are affected, but the rates are higher in men than in women. The causes vary as per the age groups as traumas affect mainly children and elderly, and traffic accidents and violence affect more of adolescents and young adults. ${ }^{3}$ Data from various studies indicate wide variation in the incidence and prevalence of psychiatric disorders after TBI, but they are definitely higher as compared with general population. Therefore, this review was undertaken to assess the psychosocial impact of brain injury on an individual.

Also, the unpublished data of $56 \mathrm{TBI}$ cases at our university hospital with 3 weeks to 9 months follow-up revealed that 30 (53.5\%) of 56 patients had one or other psychiatric disorders. This incidence seems to be very high and is important

\section{received}

September 24, 2018

accepted after revision

October 29, 2018

published online

April 22, 2019 because our university catches patients from rural areas of Uttar Pradesh; thus, it appears that the people in rural areas are more vulnerable for emotional and psychological disturbances.

\section{Impact on Individual}

\section{Depression}

The incidence rate of depression post TBI vary from 15.3 to $33 \%$ and prevalence rate from 18.5 to $61 \%{ }^{4}$ Symptoms vary from transitory responses to stressing situations to pathologic conditions, and also there is coexistence of symptoms of depression, adjustment disorder, and grief. ${ }^{5}$ Also, it is difficult to differentiate somatic symptoms of depression from symptoms directly caused by TBI. The symptoms include fatigue, less involvement in activities, insomnia, decreased appetite, and concentration. ${ }^{6}$

Depression after TBI may occur due to reduction in left prefrontal gray matter volume, ${ }^{7}$ lesions in dorsolateral prefrontal cortex and left basal ganglia, ${ }^{8}$ and also in lateral and medial frontal lobe, ${ }^{9}$ leading to rupture of neural circuits of the prefrontal cortex, amygdala, hippocampus, basal ganglia, and thalamus. This leads to mood disorders ${ }^{10}$ and
๑2019 Neurological Surgeons'

Society of India
License terms

$(\circledast) \Theta \circledast$ 10.1055/s-0039-1687713

ISSN 2277-954X. 
also the low levels of serotonin encountered after TBI may cause emotional changes, disinhibition, and aggression seen after TBI. The lesion in hippocampus and alteration in its morphology has also been reported in cognitive and depressive disorders. ${ }^{11,12}$

Poorer social functioning, 8,13 high levels of work dissatisfaction, unemployment,, ${ }^{7,14}$ low economic status, ${ }^{7}$ less education, ${ }^{15}$ and lack of close personal relationships ${ }^{13}$ have been reported in patients who develop depression following TBI. Also, psychiatric comorbidity is common in depression after TBI. Frequently depression and anxiety coexist mainly related to injuries in the right hemisphere. ${ }^{16}$ Isolated depression was more in lesions in the anterior areas on the left. ${ }^{7}$ Also in our findings, 3 of our 28 cases having left-sided lesions had depression whereas 4 had behavioral disorders, and further, the behavioral disorders and depression coexisted in 2. However, 1 of 17 right-sided lesions had depression. Thus, it appears that psychiatric disorders are encountered more in left-sided lesions as compared with right.

\section{Mania}

The reported prevalence is $4.2 \%$ for mania directly caused by $\mathrm{TBI}^{17}$ and increases to $9 \%$ within 12 months of follow-up. ${ }^{18}$ The symptoms include aggression, irritable moods, and euphoria. ${ }^{19}$ It is associated with lesions in the temporal basal poles and orbitofrontal cortex mainly in the right hemisphere. ${ }^{18-21}$ Also, it has been reported that there are focal lesions in areas connected to the limbic system in the right hemisphere, or anterior subcortical atrophy, lack of inhibitory function of the frontal cortex on subcortical limbic structures due to abnormalities in these circuits. ${ }^{22}$ The bipolar disorders are common following TBI. ${ }^{23}$

In our study, mania was not documented in any of the 30 cases, although there were four pure temporal lesions, two on either side barring frontotemporal which were six.

\section{Obsessive-Compulsive Disorder}

The prevalence varies between 0.7 and $1.6 \%$ and is similar to the general population. ${ }^{17}$ The main symptoms include obsessive slowness and compulsive exercise practice. Patients with obsessive slowness had compromised performance in neuropsychological tests for executive function, memory, and language..$^{24,25}$ Obsessive-compulsive disorders (OCDs) are mainly related to lesions in frontal and subcortical areas, mainly the orbitofrontal cortex, caudate nucleus, and anterior cingulate cortex..25,26

There is lack of study related to psychosocial factors in OCD after TBI. It is a condition with a biological basis, but it disrupts the rehabilitation process. Psychiatric comorbidity is common in patients with OCD after TBI. ${ }^{27}$

\section{Posttraumatic Stress Disorder}

The reported prevalence is $13.9 \%$ in post TBI cases mainly influenced by the severity of TBI and posttraumatic amnesia due to the formation of pathologic memories. Posttraumatic stress disorder (PTSD) symptoms were not reported in patients who had brief episode of unconsciousness and but had developed amnesia after TBI. ${ }^{28-30}$ The increase in the astrocytic protein S-100B has been reported in PTSD cases following TBI 1 year later $^{31}$ in patients in whom traumatic memories involved amygdala, hippocampus, and other related structures. ${ }^{32}$

Patients with post TBI PTSD had reduced quality of life, poorer productivity functioning, ${ }^{33}$ and reduced insight. ${ }^{34} \mathrm{Also}$, the comorbidity with depression and anxiety is common in PTSD after TBI. ${ }^{33-36}$

\section{Psychotic Disorders}

Post TBI psychosis is rare, and the reported incidence is 0.1 to $9.8 \% .^{37}$ The studies revealed that psychotic patients are more predisposed to suffer trauma ${ }^{38}$ and genetic background for schizophrenia increases this..$^{39}$ In the acute phase of TBI, the psychotic symptoms are delirium, delusions, reference, control, and grandiosity ${ }^{40}$ whereas the hallucinations appeared later (i.e., $>2$ years after the TBI) and may be auditory or visual. Aggressive behavior along with negative symptoms, disorganization, and catatonia were also reported. Prodrome symptoms include depression, antisocial and inappropriate social behavior, social withdrawal, and deterioration at work. ${ }^{41}$

Post TBI psychoses had electroencephalographic abnormalities in the temporal lobes that may be accompanied with seizures, ${ }^{42}$ also the focal lesions or brain atrophy in the frontal and temporal lobes. ${ }^{40-44}$ The increased susceptibility has been reported in patients with neurologic diseases or previous TBI. ${ }^{42}$

The psychotic symptoms result from impairment of neural circuits in the frontal and the temporal lobes, leading to an increase in the temporal limbic activity. There is lack of studies related to psychosocial factors in psychosis after TBI. ${ }^{45}$

\section{Disorders Related to Alcohol}

Alcohol is a psychoactive substance and is a leading cause of traffic accidents, falls, and violence leading to TBI. Alcohol dependence was reported in $24.1 \%$ and abuse in $10.8 \%$ of the TBI cases. ${ }^{46}$ The brain atrophy has been reported in TBI patients with history of moderate or heavy use of alcohol ${ }^{47}$ along with reduction in prefrontal gray matter volume. ${ }^{10}$ The neuronal loss related to alcohol has been reported in the frontal cortex, hypothalamus, cerebellum, hippocampus, amygdale, and locus coeruleus. ${ }^{48}$

Traumatic brain injury and alcohol use individually produced mild alterations in event-related potential testing, but changes were greater when both conditions coexist. ${ }^{49}$

Also, patients who did not sustain abstinence after TBI had more mood disorders ${ }^{10}$ whereas depression, anxiety, suicidal thoughts, violent behavior, difficulties for concentration, and use of cannabis were reported in the individuals with previous TBI along with higher rates of depressive and anxiety symptoms, antisocial personality, and suicidal attempts..$^{50,51}$ 


\section{Personality Changes}

Apathy

Apathy means disorders of decreased motivation, abulia, and akinetic mutism. The incidence varies from 10 to $46.4 \% .^{52,53}$ It is mainly seen in the lesions involving the subcortical areas or right hemisphere, causing damage to cortico-striatal-pallidalthalamic pathways involving the anterior cingulate cortex, accumbens nucleus, ventral pallidum, and medial dorsal thalamic nucleus, which are the mediators of motivation leading to akinetic mutism, abulia, and apathy ${ }^{54}$ Further, the orbitofrontal cortex, amygdala, hippocampus, and tegmental ventral area are also involved in the motivational state related to rewards. Lesions in these structures also produce apathetic symptoms. Dopamine is the main neurotransmitter linked to apathy as it has role in the mechanisms of novelty seeking, reward, and response to unexpected events. ${ }^{55}$

\section{Affective Lability}

These include emotional instability or rapid mood changes, involuntary emotional expression disorder, and pathologic laughing and crying, ${ }^{56}$ which is unrelated to the subjacent mood or independent from usual provoking stimuli. ${ }^{55,57}$ Also associated are aggression and anxiety in the left-sided frontal lobe lesions. It has been reported that impairment of cerebro-ponto-cerebellar pathways leads to incapability of the cerebellar structures to get adjusted to the execution of laughing or crying according to the environmental stimuli, thus leading to inappropriate or chaotic emotional expression. $^{58}$ The various neurotransmitters involved in these expressions are serotonin, dopamine, and glutamate. ${ }^{59}$

\section{Aggression}

Aggression is damaging, threatening, or intimidating behavior that may be impulsive or premeditated or episodic dyscontrol, with recurrent crises of out-of-proportion fury due to provocation or frustration ${ }^{60,61}$ along with the antisocial behavior withthe inconsideration for moral and social principles. ${ }^{62,63}$ The main characteristics of aggression after TBI are impulsivity and anger ${ }^{64}$ with the incidence of 14.4 to $33.7 \% .{ }^{16,65}$ Also, it is associated with substance abuse, male sex, TBI severity, intelligence level, and low socioeconomic status. ${ }^{5,66-70}$

The impulsive aggression may result from failure to regulate negative emotions, such as anger. Threatening environmental stimuli are transmitted to amygdala, from where they are relayed to the basal ganglia where they are integrated with social information from the orbitofrontal cortex. The behavioral responses are then initiated through projections toward the other cortical areas, hypothalamus, or brainstem. The orbitofrontal cortex, dorsolateral prefrontal cortex, and anterior cingulate cortex inhibit the activity of amygdala, thus forming a regulatory mechanism that is lost in patients with injuries in these areas leading to the propensity to impulsive aggression. ${ }^{71}$ The studies have reported the role of serotonin in aggressive behavior ${ }^{62,72}$ along with polymorphisms in the tryptophan-hydroxylase enzyme gene. ${ }^{71}$

\section{Other Personality Changes}

The personality changes reported in post TBI cases are behavioral disinhibition, aberrant sexual behavior, hypersexuality, moria, and self-awareness impairment. ${ }^{21,73-75}$ These are attributed to the frontal lobe impairment as it modulates the primary responses that come from other regions, such as the limbic system and motor cortex. ${ }^{20}$

\section{Conclusion}

Reviews of various studies reveal that TBI affects the individual adversely psychosocially. We also noted different psychiatric disorders in post head injury cases during their follow-up, which included depression, behavioral disorders, cognitive disorders, memory impairment, anxiety disorders, stress-related headache, vertigo, irritability and sleep disorders, etc. The incidence was as high as 53.5\% in a rural university catering mainly rural population.

In the Indian context, TBI and psychiatric disorders related to it have special importance as the road traffic accidents are higher in India, so psychiatric disorder follow-up is also common. Main psychiatric disorders are impulsive or irritable behavior followed by cognitive changes, depression, and behavioral problems that may be stress related. Often, these things are ignored, which may hamper productivity of the country. A detailed analysis with well-planned study will reveal better outcome.

\section{Conflict of Interest}

None.

\section{References}

1 Langlois JA, Rutland-Brown W, Thomas KE. Traumatic brain injury in the United States: emergency department visits, hospitalizations, and deaths. Atlanta, GA: Centers for Disease Control and Prevention, National Center for Injury Prevention and Control; 2006

2 Binder S, Corrigan JD, Langlois JA. The public health approach to traumatic brain injury: an overview of CDC's research and programs. J Head Trauma Rehabil 2005;20(3):189-195

3 Tagliaferri F, Compagnone C, Korsic M, Servadei F, Kraus J. A systematic review of brain injury epidemiology in Europe. Acta Neurochir (Wien) 2006;148(3):255-268, discussion 268

4 Kim E, Lauterbach EC, Reeve A, et al; ANPA Committee on Research. Neuropsychiatric complications of traumatic brain injury: a critical review of the literature (a report by the ANPA Committee on Research). J Neuropsychiatry Clin Neurosci 2007;19(2):106-127

5 Rosenthal M, Christensen BK, Ross TP. Depression following traumatic brain injury. Arch Phys Med Rehabil 1998;79(1):90-103

6 Sliwinski M, Gordon WA, Bogdany J. The Beck Depression Inventory: is it a suitable measure of depression for individuals with traumatic brain injury? J Head Trauma Rehabil 1998;13(4):40-46

7 Jorge RE, Robinson RG, Moser D, Tateno A, Crespo-Facorro B, Arndt $\mathrm{S}$. Major depression following traumatic brain injury. Arch Gen Psychiatry 2004;61(1):42-50 
8 Fedoroff JP, Starkstein SE, Forrester AW, et al. Depression in patients with acute traumatic brain injury. Am J Psychiatry 1992;149(7):918-923

9 Paradiso S, Chemerinski E, Yazici KM, Tartaro A, Robinson RG. Frontal lobe syndrome reassessed: comparison of patients with lateral or medial frontal brain damage. J Neurol Neurosurg Psychiatry 1999;67(5):664-667

10 Jorge RE, Starkstein SE, Arndt S, Moser D, Crespo-Facorro B, Robinson RG. Alcohol misuse and mood disorders following traumatic brain injury. Arch Gen Psychiatry 2005;62(7):742-749

11 Campbell S, Macqueen G. The role of the hippocampus in the pathophysiology of major depression. J Psychiatry Neurosci 2004;29(6):417-426

12 Jorge RE, Acion L, Starkstein SE, Magnotta V. Hippocampal volume and mood disorders after traumatic brain injury. Biol Psychiatry 2007;62(4):332-338

13 Gomez-Hernandez R, Max JE, Kosier T, Paradiso S, Robinson RG. Social impairment and depression after traumatic brain injury. Arch Phys Med Rehabil 1997;78(12):1321-1326

14 Seel RT, Kreutzer JS, Rosenthal M, Hammond FM, Corrigan JD, Black K. Depression after traumatic brain injury: a National Institute on Disability and Rehabilitation Research Model Systems multicenter investigation. Arch Phys Med Rehabil 2003;84(2):177-184

15 Dikmen SS, Bombardier CH, Machamer JE, Fann JR, Temkin NR. Natural history of depression in traumatic brain injury. Arch Phys Med Rehabil 2004;85(9):1457-1464

16 Jorge RE, Robinson RG, Starkstein SE, Arndt SV. Depression and anxiety following traumatic brain injury. J Neuropsychiatry Clin Neurosci 1993c;5(4):369-374

17 van Reekum R, Cohen T, Wong J. Can traumatic brain injury cause psychiatric disorders? J Neuropsychiatry Clin Neurosci 2000;12(3):316-327

18 Jorge RE, Robinson RG, Starkstein SE, Arndt SV, Forrester AW, Geisler FH. Secondary mania following traumatic brain injury. Am J Psychiatry 1993;150(6):916-921

19 Shukla S, Cook BL, Mukherjee S, Godwin C, Miller MG. Mania following head trauma. Am J Psychiatry 1987;144(1):93-96

20 Starkstein SE, Boston JD, Robinson RG. Mechanisms of mania after brain injury. 12 case reports and review of the literature. J Nerv Ment Dis 1988;176(2):87-100

21 Robinson RG, Boston JD, Starkstein SE, Price TR. Comparison of mania and depression after brain injury: causal factors. Am J Psychiatry 1988;145(2):172-178

22 Adler CM, DelBello MP, Strakowski SM. Brain network dysfunction in bipolar disorder. CNS Spectr 2006;11(4):312320, quiz 323-324

23 DelBello MP, Soutullo CA, Zimmerman ME, et al. Traumatic brain injury in individuals convicted of sexual offenses with and without bipolar disorder. Psychiatry Res 1999;89(3):281286 PubMed

24 Berthier ML, Kulisevsky J, Gironell A, Heras JA. Obsessive-compulsive disorder associated with brain lesions: clinical phenomenology, cognitive function, and anatomic correlates. Neurology 1996;47(2):353-361

25 Berthier ML, Kulisevsky JJ, Gironell A, López OL. Obsessive compulsive disorder and traumatic brain injury: behavioral, cognitive, and neuroimaging findings. Neuropsychiatry Neuropsychol Behav Neurol 2001;14(1):23-31

26 Bilgic B, Baral-Kulaksizoglu I, Hanagasi $\mathrm{H}$, et al. Obsessive-compulsive disorder secondary to bilateral frontal damage due to a closed head injury. Cogn Behav Neurol 2004;17(2):118-120

27 Ogai M, Iyo M, Mori N, Takei N. A right orbitofrontal region and OCD symptoms: a case report. Acta Psychiatr Scand 2005;111(1):74-76, discussion 76-77
28 Grados MA. Obsessive-compulsive disorder after traumatic brain injury. Int Rev Psychiatry 2003;15(4):350-358

29 Elbert T, Schauer M. Burnt into memory. Nature 2002;419(6910):883

30 Sbordone RJ, Liter JC. Mild traumatic brain injury does not produce post-traumatic stress disorder. Brain Inj 1995;9(4):405-412

31 Mayou R, Bryant B, Duthie R. Psychiatric consequences of road traffic accidents. BMJ 1993;307(6905):647-651

32 Sojka P, Stålnacke BM, Björnstig U, Karlsson K. One-year follow-up of patients with mild traumatic brain injury: occurrence of post-traumatic stress-related symptoms at follow-up and serum levels of cortisol, S-100B and neuron-specific enolase in acute phase. Brain Inj 2006;20(6):613-620

33 Gil S, Caspi Y, Ben-Ari I, Klein E. Memory of the traumatic event as a risk factor for the development of PTSD: lessons from the study of traumatic brain injury. CNS Spectr 2006;11(8):603-607

34 Bryant RA, Marosszeky JE, Crooks J, Baguley IJ, Gurka JA. Interaction of posttraumatic stress disorder and chronic pain following traumatic brain injury. J Head Trauma Rehabil 1999;14(6):588-594

35 Williams WH, Evans JJ, Needham P, Wilson BA. Neurological, cognitive and attributional predictors of posttraumatic stress symptoms after traumatic brain injury. J Trauma Stress 2002;15(5):397-400

36 Glaesser J, Neuner F, Lütgehetmann R, Schmidt R, Elbert T. Posttraumatic stress disorder in patients with traumatic brain injury. BMC Psychiatry 2004;4:5

37 Bombardier $\mathrm{CH}$, Fann JR, Temkin N, et al. Posttraumatic stress disorder symptoms during the first six months after traumatic brain injury. J Neuropsychiatry Clin Neurosci 2006;18(4):501-508

38 David AS, Prince M. Psychosis following head injury: a critical review. J Neurol Neurosurg Psychiatry 2005;76(Suppl 1):i53-i60

39 Fann JR, Burington B, Leonetti A, Jaffe K, Katon WJ, Thompson RS. Psychiatric illness following traumatic brain injury in an adult health maintenance organization population. Arch Gen Psychiatry 2004;61(1):53-61

40 Malaspina D, Goetz RR, Friedman JH, et al. Traumatic brain injury and schizophrenia in members of schizophrenia and bipolar disorder pedigrees. Am J Psychiatry 2001;158(3):440-446

41 Sachdev P, Smith JS, Cathcart S. Schizophrenia-like psychosis following traumatic brain injury: a chart-based descriptive and case-control study. Psychol Med 2001;31(2):231-239

42 Zhang Q, Sachdev PS. Psychotic disorder and traumatic brain injury. Curr Psychiatry Rep 2003;5(3):197-201

43 Fujii DE, Ahmed I. Risk factors in psychosis secondary to traumatic brain injury. J Neuropsychiatry Clin Neurosci 2001;13(1):61-69

44 Achté KA, Hillbom E, Aalberg V. Psychoses following war brain injuries. Acta Psychiatr Scand 1969;45(1):1-18

45 Buckley P, Stack JP, Madigan C, et al. Magnetic resonance imaging of schizophrenia-like psychoses associated with cerebral trauma: clinicopathological correlates. Am J Psychiatry 1993;150(1):146-148

46 Corrigan JD. Substance abuse as a mediating factor in outcome from traumatic brain injury. Arch Phys Med Rehabil 1995;76(4):302-309

47 Parry-Jones BL, Vaughan FL, Miles Cox W. Traumatic brain injury and substance misuse: a systematic review of prevalence and outcomes research (1994-2004). Neuropsychol Rehabil 2006;16(5):537-560

48 Wilde EA, Bigler ED, Gandhi PV, et al. Alcohol abuse and traumatic brain injury: quantitative magnetic resonance 
imaging and neuropsychological outcome. J Neurotrauma 2004;21(2):137-147

49 Harper C. The neuropathology of alcohol-specific brain damage, or does alcohol damage the brain? J Neuropathol Exp Neurol 1998;57(2):101-110

50 Baguley IJ, Felmingham KL, Lahz S, Gordan E, Lazzaro I, Schotte DE. Alcohol abuse and traumatic brain injury: effect on event-related potentials. Arch Phys Med Rehabil 1997;78(11):1248-1253

51 Felde AB, Westermeyer J, Thuras P. Co-morbid traumatic brain injury and substance use disorder: childhood predictors and adult correlates. Brain Inj 2006;20(1):41-49

52 Mainio A, Kyllönen T, Viilo K, Hakko H, Särkioja T, Räsänen P. Traumatic brain injury, psychiatric disorders and suicide: a population-based study of suicide victims during the years 1988-2004 in Northern Finland. Brain Inj 2007;21(8):851-855

53 Marin RS, Wilkosz PA. Disorders of diminished motivation. J Head Trauma Rehabil 2005;20(4):377-388

54 Prigatano GP. Personality disturbances associated with traumatic brain injury. J Consult Clin Psychol 1992;60(3): 360-368

55 Arciniegas DB, LauterbachEC, Anderson KE, etal. The differential diagnosis of pseudobulbar affect (PBA). Distinguishing PBA among disorders of mood and affect. Proceedings of a roundtable meeting. CNS Spectr 2005;10(5):1-14, quiz 15-16

56 Mega MS, Cohenour RC. Akinetic mutism: disconnection of frontal-subcortical circuits. Neuropsychiatry Neuropsychol Behav Neurol 1997;10(4):254-259

57 Cummings JL, Arciniegas DB, Brooks BR, et al. Defining and diagnosing involuntary emotional expression disorder. CNS Spectr 2006;11(S6):1-7

58 Zeilig G, Drubach DA, Katz-Zeilig M, Karatinos J. Pathological laughter and crying in patients with closed traumatic brain injury. Brain Inj 1996;10(8):591-597

59 Parvizi J, Anderson SW, Martin CO, Damasio H, Damasio AR. Pathological laughter and crying: a link to the cerebellum. Brain 2001;124(Pt 9):1708-1719

60 Rabins PV, Arciniegas DB. Pathophysiology of involuntary emotional expression disorder. CNS Spectr 2007;12(4, Suppl 5): $17-22$

61 Sandel ME, Mysiw WJ. The agitated brain injured patient. Part 1: Definitions, differential diagnosis, and assessment. Arch Phys Med Rehabil 1996;77(6):617-623
62 Gordon N. Episodic dyscontrol syndrome. Dev Med Child Neurol 1999;41(11):786-788

63 Anderson K, Silver JM. Modulation of anger and aggression. Semin Clin Neuropsychiatry 1998;3(3):232-242

64 Blair RJ, Cipolotti L. Impaired social response reversal. A case of “acquired sociopathy. Brain 2000;123(Pt 6):1122-1141

65 Pelegrín-Valero CA, Gómez-Hernández R, Muñoz-Céspedes JM, Fernández-Guinea SD, Tirapu-Ustarroz J. [Nosologic aspects of personality change due to head trauma] [in Spanish]. Rev Neurol 2001;32(7):681-687

66 Yudofsky SC, Silver JM, Jackson W, Endicott J, Williams D. The Overt Aggression Scale for the objective rating of verbal and physical aggression. Am J Psychiatry 1986;143(1):35-39

67 Grafman J, Schwab K, Warden D, Pridgen A, Brown HR, Salazar AM. Frontal lobe injuries, violence, and aggression: a report of the Vietnam Head Injury Study. Neurology 1996;46(5):1231-1238

68 Rapoport M, McCauley S, Levin H, Song J, Feinstein A. The role of injury severity in neurobehavioral outcome 3 months after traumatic brain injury. Neuropsychiatry Neuropsychol Behav Neurol 2002;15(2):123-132

69 Tateno A, Jorge RE, Robinson RG. Clinical correlates of aggressive behavior after traumatic brain injury. J Neuropsychiatry Clin Neurosci 2003;15(2):155-160

70 Wood RL, Liossi C. Neuropsychological and neurobehavioral correlates of aggression following traumatic brain injury. J Neuropsychiatry Clin Neurosci 2006;18(3):333-341

71 Baguley IJ, Cooper J, Felmingham K. Aggressive behavior following traumatic brain injury: how common is common? J Head Trauma Rehabil 2006;21(1):45-56

72 Davidson RJ, Putnam KM, Larson CL. Dysfunction in the neural circuitry of emotion regulation-a possible prelude to violence. Science 2000;289(5479):591-594

73 Higley JD, Mehlman PT, Poland RE, et al. CSF testosterone and 5-HIAA correlate with different types of aggressive behaviors. Biol Psychiatry 1996;40(11):1067-1082

74 Simpson G, Blaszczynski A, Hodgkinson A. Sex offending as a psychosocial sequela of traumatic brain injury. J Head Trauma Rehabil 1999;14(6):567-580

75 Rommel O, Widdig W, Mehrtens S, Tegenthoff M, Malin JP. ["Frontal lobe syndrome" caused by severe head trauma or cerebrovascular diseases]. Nervenarzt 1999;70(6):530-538 